\title{
Editorial
}

\section{Applied Sports Science to Military and Police Activities}

\author{
Vicente Javier Clemente-Suárez", Ricardo Jorge Fernandes and Argyris Toubekis
}

Department of Motricity, Human Performance and Sport Management. European University of Madrid. C/ Tajo s/n, Villaviciosa de Odón, 28670 Madrid, Spain

Ancient civilizations were using fighting as a means of survival and dominance. All of their military activities were based on body actions requiring skill, agility and stamina. In the present era, despite the actual technologically advanced equipments, a major part of the military and police personnel undertakes critical bodily actions for short duration periods within a battle. Additionally, military and police as well as fire-fighting personnel, face extreme environmental and other types of body stress for long duration periods. Actually, the military and police activities produce a high organic response, a fact that influences the structure of military and police corps, increasing the necessity of highly trained subjects in them, both physically and psychologically.

In modern times, sports sciences have grown and hold an increasingly important role in the strategies applied for increasing sports performance. With the increasing number of sports science laboratories and researchers, science and technology applied to sports have increased, reaching a highly applied knowledge to the field of sports sciences. This knowledge has sometimes been applied very efficiently to the military areas, especially in wars or conflicts between various factions or nations. Improvements in training methods and systems, in the psychological, physiological

*Address correspondence to this author at the Department of Motricity, Human Performance and Sport Management. European University of Madrid. C/ Tajo s/n, Villaviciosa de Odón, 28670 Madrid. Spain;

Tel: +34902232350; Fax: 0034-911413585;

E-mail: vicentejavier.clemente@uem.es and morphological selection processes and nutritional strategies were some of the military fields raised due to the scientific knowledge acquired from sports science research.

In current theatres of operation, different warfare actions are combined, predominantly the asymmetrical warfare (not in a defined battlefield) that is characterized by combat in urban areas in constant evolution with presence of civilians. These asymmetrical conflicts, which are also the normal work field of the police, are constantly changing and the soldier/police officer has to be prepared for unexpected attacks or melee combats. These new requirements of actual operation areas have led to the need to improve the melee training systems, making them more efficient and adapted to the new circumstances, and to create new methods of learning the basic military techniques (e.g. shackled or the use of rifle), to improve the learning processes and qualities of trainers and teachers of both police and military academies, as well as nutritional strategies in combat.

The present special issue "Applied sports science to military and police activities" of The Open Journal of Sports Sciences aims to divulge to the reader the latest studies in various fields of sports science applied to different areas of police and military field. In addition, the present issue also presents the most important studies about the fire-fighters, because the characteristics of their work are also closely linked to sports science. So, we hope that the readers of this special issue find the content selected interesting and attractive and that the information presented will be practical and useful for the professionals in military, police and fire fighting areas. 